\title{
Leadless and symbiotic cardiac pacemakers; as an alternative to conventional pacemakers
}

\author{
Mehmet Cosgun, 'Dilmaz Gunes, Ibrahin Donmez \\ Department of Cardiology, Bolu Abant Izzet Baysal University, School of Medicine, Bolu, Turkey
}

\begin{abstract}
A BSTRACT
There have been considerable advancements in technology since the first permanent pacemaker was implanted in 1960. A subcutaneous generator and battery module are connected to one or more endocardial leads in the conventional pacemaker implantation. Despite their proven efficiency, traditional permanent pacemakers have a number of drawbacks their use has been linked to potential complications during implantation procedure and also during follow-up period; among the most notable ones are lead malfunction, limited battery life, and device-related infections. Therefore, there had been tremendous efforts to avoid such complications and to increase battery life. In this Review, we explore new electronic devices, leadless pacemaker systems and symbiotic cardiac pacemakers, designed to avoid these current limitations.
\end{abstract}

Key words: Heart, cardiac surgical procedures, instrumentation, cardiac pacemaker, leadless, symbiotic.

$\triangle$ Dr. Mehmet Cosgun

Department of Cardiology, Bolu Abant Izzet Baysal University, School of Medicine, Bolu, Turkey

E-mail: coskun44@gmail.com

Received: 2021-05-07 / Revisions: 2021-05-25

Accepted: 2021-05-27 / Published online: 2021-06-01

\section{Leadless Cardiac Pacemakers}

Approximately one million new pacemakers are implanted each year [1]. Complications are seen in approximately $10 \%$ of patients during and after the implantation of permanent pacemakers [2,3]. These complications which are primarily lead- or pocket-related, include pneumothorax, tamponade, hematoma, venous obstruction, lead breakage/dislocation, tricuspid regurgitation, and infection [4-6]. Therefore there had been continuing efforts to improve pacemaker technology for easy use and to avoid complications.

To address these issues, Leadless pacemaker (LPM) research was started after the second half of the 20th century. LPM was successfully implanted in the right ventricle for the first time in 2012 [7-9]. Due to its single chamber pacing feature only, it is suitable for use in a limited number of indications. These are (1) Permanent atrial fibrillation (AF) with atrioventricular (AV) block or AF with a slow ventricular response (2) Sinus rhythm with $2^{\text {nd }} / 3^{\text {rd }}$ degree AV block and significant comorbidities or (3) sinus bradycardia with infrequent pauses or unexplained syncope with electrophysiology findings (like prolonged HV interval) [10]. The two LPM systems (Nanostim ${ }^{\mathrm{TM}}$ (St. Jude Medical, Inc., St. Paul, MN, USA) and Micra ${ }^{\mathrm{TM}}$ transcatheter pacing system (TPS) (Medtronic, Inc., Minneapolis, MN, USA)) that are currently available have demonstrated comparable performance and safety results. Data for both Nanostim and Micra showed an equally high degree of implant success, ranging from 99 to $95 \%$. The overall non-complication rate for the Nanostim was around 94\% and for the Micra it was around 96-98.5\%. Both LPM 
system are similarly implemented with fluoroscopic guidance in the catheterization laboratory. Dedicated introducer sheaths are used which measure 18/21 French for Nanostim LCP and 23/27 French for Micra TPS. Percutaneously a LPM device is introduced through the femoral vein that is mounted on the deflectable tip in the end of the delivery catheter. Then, through the vena cava inferior, to the right atrium and through the tricuspid valve, the deflectable delivery system is moved to the right ventricular myocardium. The device is fixated by either a screw-in helix (Nanostim LCP) or nitinol tines (Micra TPS). The device is discharged from the delivery system following an electrical threshold test and a tug test for stability. The two devices have been designed to be removed after implantation using a snare $[11,12]$.

Due to the fact that the device is leadless, electrode bending and possible damage to the lead are prevented. Device pocket and transvenous lead removal can also minimize some of the long-term pacemaker complications such as tricuspid valve regurgitation and thromboembolism [13]. Leadless pacemaker implantation appears to have a slightly higher acute period complication rate compared to traditional pacemaker (TPM) implantation $(4.8 \%$ versus $4.0 \%$ ) [14]. This is probably due to unfamiliarity of operators to new LPM system technology and lack of experience for their implantation.

The results of the Micra study showed that LPM has a $48 \%$ lower complication rate, $47 \%$ lower yearly hospitalizations and $82 \%$ less pacemaker re-insertion rate than TPM [15]. A prospective, multicenter, non-randomized trial with the safety of the LCP Nanostim in a real world was the LEADLESS Observational study. In 95 percent (285 of 300 ) of the patients, freedom from grave adverse events was observed after 6 months of Nanostim LCP implantation. However, cardiac perforation $(1.3 \%, \mathrm{n}=4)$ and vascular complications $(1.3 \%, \mathrm{n}=4)$ were reported [16]. Sattar et al. searched the complication rates of conventional and leadless pacemakers in a retrospective review published in 2020. They reported that LPMs had better safety profiled with lower electrode dislodgement (56\% vs $7 \%, \mathrm{p}<0.0001$ ), pocket site infection ( $16 \%$ vs $3.4 \%, \mathrm{p}=0.02)$, and lead fracture rate ( $8 \%$ vs $0 \%, \mathrm{p}=0.04)$. However, LPMs had a statistically non-significant twotimes high risk of pericardial effusion $(8 \%$ vs $4 \%, \mathrm{p}=0.8$ ) [17].

In all, comparable performance and safety results were demonstrated by the 2 LPM systems. Pneumothorax and infection with pocket/lead did not occur as expected. The leadless procedure was however associated with femoral vascular complications unique to percutaneous insertion of the device, intraoperative repositioning and a moderate risk of cardiac perforation that lead to pericardial effusion. Despite many advantages in terms of pacemaker pocket and lead-related complications risk reduction, LPM therapy is currently available only for VVI pacing, which represents $<15 \%$ of the pacemaker population. It is difficult to compare complication rates of 2 leadless pacemaker systems exactly, due to several differences in study design. The main difference was the definition used for the primary safety outcome in the studies. If the major complication criteria in the Micra TPS study were used in the Leadless II study, the reported complication rate could decrease from $6.5 \%$ to $4.9 \%$. There was a difference in device displacement rate between LCP and TPS (2.3\% vs $0 \%$ ). This indicates that the screw fastening mechanism of the LCP may result in a higher risk of dislocation. Experience is very 
important in fixing the LCP correctly. Actually evidence for this was seen in the European LEADLESS Observational Trial. At the beginning of the study, fatal pericardial tamponade was observed in 2 of 147 patients and the study was stopped. After the physician training program, this rate decreased to 0 in 93 patients [14]. In the Micra study, there was no evidence between operator experience and major complications [18]. On the other hand, the researchers showed that patients with older age, female sex, low body mass index, and chronic lung disease are more likely to suffer from cardiac injury [19]. Estimated battery life calculated using actual usage data at 6-month follow-up is 15.0 years for LCP and 12.5 years for TPS [20]. However, different methods have been used to estimate the battery life for 2 devices and have a significant effect on the predicted longevity. LCP, ISO standard 60 beats / minute at $0.4 \mathrm{~ms}, 100 \%$ pacing nominal settings at $2.5 \mathrm{~V}$ were used. The TPS used an alternative nominal setting of $100 \%$ at $1.5 \mathrm{~V}$ at $0.24 \mathrm{~ms}$ at 60 beats / min. If the TPS longevity estimate was instead calculated using ISO nominal settings, the battery life would be reduced to 4.7 years [21]. Five major significant publications of these two types of LPM are compared in Table 1.

Table 1. Major clinical trials of cardiac leadless pacemaker treatment.

\begin{tabular}{|c|c|c|c|c|}
\hline Study & $\begin{array}{l}\text { Number } \\
\text { of } \\
\text { Patients }\end{array}$ & $\begin{array}{l}\text { Follow up } \\
\text { Time }\end{array}$ & Primary end point & Finding and Notes \\
\hline $\begin{array}{l}\text { LEADLESS } \\
(2014)\end{array}$ & 33 & 90 days & $\begin{array}{l}\text { Freedom from } \\
\text { complications }\end{array}$ & $\begin{array}{l}\text { The overall complication-free rate was } \\
94 \% \text { (31/33). After } 3 \text { months of follow-up, } \\
\text { the measures of pacing performance either } \\
\text { improved or were stable within the } \\
\text { accepted range. }\end{array}$ \\
\hline $\begin{array}{l}\text { LEADLESS II } \\
(2015)\end{array}$ & 526 & 180 days & $\begin{array}{l}\text { Freedom from device- } \\
\text { related serious adverse } \\
\text { events }\end{array}$ & $\begin{array}{l}\text { Observed in } 6.7 \% \text { of the patients; events } \\
\text { included device dislodgement with } \\
\text { percutaneous retrieval (in 1.7\%), cardiac } \\
\text { perforation (in } 1.3 \% \text { ), and pacing- } \\
\text { threshold elevation requiring percutaneous } \\
\text { retrieval and device replacement (in } 1.3 \% \text { ) }\end{array}$ \\
\hline $\begin{array}{l}\text { The Micra } \\
\text { Transcatheter } \\
\text { Pacing Study } \\
\text { (2015) }\end{array}$ & 744 & 183 days & $\begin{array}{l}\text { Freedom from major } \\
\text { complications related } \\
\text { to the Micra system or } \\
\text { implant procedure }\end{array}$ & $\begin{array}{l}\text { The percentage of patients free from major } \\
\text { complications is significantly higher than } \\
83 \% \text {, both low and stable thresholds is } \\
\text { significantly higher than } 80 \% \text {. }\end{array}$ \\
\hline $\begin{array}{l}\text { LEADLESS } \\
\text { Observational } \\
\text { Study } \\
(2018)\end{array}$ & 470 & 180 days & $\begin{array}{l}\text { Evaluation of safety via } \\
\text { freedom from serious } \\
\text { adverse device effects }\end{array}$ & $\begin{array}{l}\text { The rate of freedom from serious adverse } \\
\text { device effects was } 94.6 \%\end{array}$ \\
\hline $\begin{array}{l}\text { The Micra Post- } \\
\text { Approval } \\
\text { Registry } \\
(2017)\end{array}$ & 795 & 30 days & $\begin{array}{l}\text { Assess system- or } \\
\text { procedure-related } \\
\text { major complications } \\
\text { through } 30 \text { days post } \\
\text { implant. }\end{array}$ & $\begin{array}{l}\text { Major complication rate of } 1.51 \% \text {, } \\
\text { (cardiac effusion/perforation }(0.13 \%) \text {, } \\
\text { device dislodgement }(0.13 \%) \text {, and sepsis } \\
(0.13 \%))\end{array}$ \\
\hline
\end{tabular}


Promising results are expected from new studies conducted such as LPM alternative pacing modalities, devices with improved battery longevity, possibilities of devices delivering dual-chamber therapy and cardiac resynchronization therapy to expand clinical applicability and cover most indications. Leadless pacemakers have the potential to supplant conventional lead-based pacemakers for most indications.

\section{Symbiotic Cardiac Pacemakers}

Including a fixed lifespan that results in lead and/or generator replacement periodically, implantable cardiac pacemakers are not without limitations, despite technological advances. Consequently, a symbiotic pacemaker is a promising technique for dealing with these challenges.

Living organisms are rich in chemical, thermal and mechanical sources of energy [22-24]. The use of these energy sources may be a viable way of overcoming the battery capacity limit, which restricts implantable devices' long-term durability.

In 1999, Goto et al, tested an automatic power generation system (AGS) for quartz watches that converts kinetic energy into electrical energy as a power source for implantable leadless pacemakers in a dog. AGS produced 13 $\mu \mathrm{J}$ per heartbeat, thus demonstrating that AGS could provide enough energy for use in a pacemaker [25].

A nanogenerator that can harvest biomechanical energy from cardiac motion and thereby power the implanted pacemaker has been developed by Ouyang et al. in 2019. The researchers developed an implantable pacemaker comprising a power management unit, a pacemaker unit and a novel implantable triboelectric nanogenerator (iTENG), containing two triboelectric layers. The iTENG was placed between the heart and the pericardium of a pig; cardiac motion caused periodic contact and separation of the two triboelectric layers, generating electrical energy, which could be stored in the capacitor of the power management unit. The iTENGbased pacemaker successfully converted sinus arrhythmia to a rhythm of pacing in a pig with sinus arrhythmia inducted through sinus node hypothermia. This new pacemaker is described by the researchers as symbiotic because it transforms biomechanical energy from the beating heart into electricity energy for power of the pacing module [26]. The iTENG provides a promising method to harvest in vivo biomechanical energy, with advantages of wide choice of materials, high outputs, good flexibility, light weight, excellent durability and low cost.

To reach clinical applications, the advancement of minimally invasive procedures like interventional cardiac catheterization, which are commonly used in pacemaker implantation, could provide a suitable solution for symbiotic cardiac pacemaker implantation. The size, flexibility, and operability of the instruments should be viewed as a major concern in order to meet the criteria of minimally invasive surgery.

\section{Conclusion}

Clinicians are pursuing perfect systems in pacemakers that comply with the normal physiological transmission, are easy to implant, have the least complications, do not contain too many external structures, and do not need an external battery for energy, and with each discovery they are getting one step closer to this. The treatment of heart conduction system disorders is currently performed with traditional pacemakers and recently with leadless pacemakers that have been put into service for humanity for the last 10 years. 
Although randomized clinical trials are not yet available, they are expected to cover most of the pacemaker indications. Probably and hopefully, in addition to single RV pacing modality, they will be used for multicomponent, dual-chamber pacing and cardiac resynchronization therapies in near future. Symbiotic pacemakers, which achieving pacemaker energy requirement via converting biomechanical energy from the beating heart into electricity have become a favorite of researchers in recent years for cardiac pace makers and also for stimulators for nerve and muscle diseases.

Funding: The author(s) received no financial support for the research, authorship, and/or publication of this article.

Conflict of Interest: The authors declare that they have no conflict of interest.

Ethical statement: Since this research is a review study, no ethics committee decision was required.

\section{Open Access Statement}

This is an open access journal which means that all content is freely available without charge to the user or his/her institution under the terms of the Creative Commons Attribution NonCommercial License (http://creativecommons.org/licenses/bync/4.0). Users are allowed to read, download, copy, distribute, print, search, or link to the full texts of the articles, without asking prior permission from the publisher or the author.

\section{References}

[1]Mond HG, Proclemer A. The 11th world survey of cardiac pacing and implantable cardioverter-defibrillators: calendar year 2009-a World Society of Arrhythmia's project. Pacing Clin Electrophysiol. 2011;34(8)1013-27.

[2]Kirkfeldt RE, Johansen JB, Nohr EA, et al. Complications after cardiac implantable electronic device implantations: an analysis of a complete, nationwide cohort in Denmark. Eur Heart J. 2014;35(18):118694.

[3]Palmisano P, Accogli M, Zaccaria M, et al. Rate, causes, and impact on patient outcome of implantable device complications requiring surgical revision: large population survey from two centres in Italy. Europace. 2013;15(4):531-40.

[4]Udo EO, Zuithoff NP, van Hemel NM, et al. Incidence and predictors of short- and longterm complications in pacemaker therapy: the FOLLOWPACE study. Heart Rhythm. 2012;9(5):728-35.

[5]Ellenbogen KA, Hellkamp AS, Wilkoff BL, et al. Complications arising after implantation of DDD pacemakers: the MOST experience. Am J Cardiol. 2003;92(6):740-41.

[6]Johansen JB, Jørgensen OD, Møller M, et al. Infection after pacemaker implantation: infection rates and risk factors associated with infection in a population-based cohort study of 46299 consecutive patients. Eur Heart J. 2011;32(8):991-98.

[7]Vardas PE, Politopoulos C, Manios E, et al. A miniature pacemaker introduced intravenously and implanted endocardially. Preliminary findings from an experimental study. Eur J Card Pacing Electrophysiol. 1991;1:27-30.

[8]Spickler JW, Rasor NS, Kezdi P, et al. Totally self-contained intracardiac pacemaker. J Electrocardiol. 1970;3(34):325-31.

[9]Reddy VY, Knops RE, Sperzel JS, et al. Permanent leadless cardiac pacing: results of 
the LEADLESS trial. Circulation. 2014;129(14):1466-71.

[10] Gillis AM, Russo AM, Ellenbogen KA, et al. HRS/ACCF expert consensus statement on pacemaker device and mode selection. J Am Coll Cardiol. 2012;60(7):682-703.

[11] Nanostim ${ }^{\mathrm{TM}}$ Leadless Pacemaker Nanostim $^{\mathrm{TM}}$ Delivery System Catheter S1DLCP. Instructions for Use. (C) 2016 St. Jude Medical, Inc. All Rights Reserved.

[12]Micra Transcatheter Pacing System: MC1VR01. Product Specifications. http://www.medtronic.com/content/dam/me dtronic-com/products/cardiacrhythm/ pacemakers/micra-pacingsystem/documents/2016-04-micraspecification-sheet.pdf.

Accessed September 29, 2016.

[13] DeSimone CV, Friedman PA, Noheria A, et al. Stroke or transient ischemic attack in patients with transvenous pacemaker or defibrillator and echocardiographically detected patent foramen ovale. Circulation. 2013;128(13):1433-41.

[14]Tjong FV, Reddy VY. Permanent Leadless Cardiac Pacemaker Therapy: A Comprehensive Review. Circulation. 2017;135(15):1458-70.

[15]Duray GZ, Ritter P, El-Chami M, et al. Long-term performance of a transcatheter pacing system: 12-month results from the micra transcatheter pacing study. Heart Rhythm. 2017;14(5):702-709.

[16] Sperzel J, Defaye P, Delnoy PP, et al. Primary safety results from the LEADLESS observational study. EP Europace. 2018;20(9):1491-97.

[17] Sattar Y, Ullah W, Roomi S, et al. Complications of leadless vs conventional (lead) artificial pacemakers - a retrospective review. J Community Hosp Intern Med Perspect. 2020;10(4):328-33.
[18] Kowal R, Soejima K, Ritter P, et al. Relationship between operator experience and procedure outcomes with the Micra transcatheter leadless pacing system. Heart Rhythm. 2016; 13:S169.

[19]Reynolds D, Duray GZ, Omar R, et al. A leadless intracardiac transcatheter pacing system. N Engl J Med. 2016;374(6):533-41.

[20] Senaratne J, Irwin ME, Senaratne MP. Pacemaker longevity: are we getting what we are promised? Pacing Clin Electrophysiol. 2006;29(10):1044-54.

[21]Beurskens NE, Tjong FV, Knops RE. Endof-life Management of Leadless Cardiac Pacemaker Therapy. Arrhythm Electrophysiol Rev. 2017;6(3):129-33.

[22] Kumar A, Kiran R, Kumar S, et al. A comparative numerical study on piezoelectric energy harvester for selfpowered pacemaker application. Glob Chall. 2018;2(1):1700084.

[23]Deterre M, Lefeuvre E, Zhu Y, et al. Micro blood pressure energy harvester for intracardiac pacemaker. J Micro $\mathrm{S}$. 2014;23(3):651-60.

[24] Kim DH, Shin HJ, Lee H, et al. In vivo selfpowered wireless transmission using biocompatible flexible energy harvesters. Adv Funct Mater. 2017;27(25):1700341.

[25]Goto H, Sugiura T, Harada Y, et al. Feasibility of using the automatic generating system for quartz watches as a leadless pacemaker power source. Med Biol Eng Comput. 1999;37(3):377-80.

[26] Ouyang H, Liu Z, Li N, et al. Symbiotic cardiac pacemaker. Nat Commun. 2019;23;10(1):1821. 